\title{
EL INDIVIDUO EN PEDRO DE JUAN OLIVO
}

A. Perez-Estevez ${ }^{*}$

SINTESE - Em Olivo o universal perde toda a consistência ontológica. $\mathrm{O}$ que existe de fato são os seres singulares. $\mathrm{O}$ universal é um produto da re-presentação humana que, através das "razões reais", compreende o individual de forma universal. Entre o mundo da realidade individual e o mundo da universalidade inteligida e expressa pela linguagem, há uma distância muito maior do que supunham seus antecessores.

\begin{abstract}
In Olivi's philosophy the universal looses completely its ontological consistence. The singular beings are in fact truely existent beings. The universal is a product of the human representation, which by means of the rationes reales comprises universally the individual. Between the world of the individual reality and that of the universality intellectually apprehended there is a very greater distance than Olivi's predecessors had supposed.
\end{abstract}

\section{I - Introducción}

Pedro de Juan Olivo reside en París entre los años de 1268 y 1273 en donde conoce y trata con sus hermanos de Orden, Guillermo de Mara, Enrique de Arras, Juan Pecham, Mateo de Aquasparta, Rogerio Marston, Ricardo de Mediavilla y por supuesto Buenaventura por esos años General de la Orden Franciscana. Se recibe de bachiller bíblico en 1270, el año en que Obispo Tempier (10 de Diciembre) publica su decreto para frenar el influjo creciente de la doctrina aristotélica, algunas de cuyas tesis chocaban con la doctrina tradicional católica enseñada en la Facultad de Teología. Uno de los errores condenados decía referencia a que 'Dios no conoce las cosas particulares' y tocaba muy de refilón el problema de la 'individualidad'. Siete años más tarde el mismo Obispo Tempier en respuesta a una petición de Juan XXI condena 219 proposiciones erróneas entre las que se encuentran que 'Dios no puede multiplicar los indivíduos de la misma especie sin materia', que 'las formas no admiten división a no ser en razón de la materia' y que 'debido a que las inteligencias no tienen materia, Dios no puede hacer muchas en una misma especie...', tal como lo relata Enrique de Gante en su Quodlibet II, q. 8, p. 45. ${ }^{1}$ El pro-

\section{Universidad del Zulia, Maracaibo.}

1 Enrique de Gante, Quodlibet II, Leuven University Press, 1983, q. 8, p. 45: Unus enim illorum articulorum dicit sic: 'Ouod Deus non possit multiplicare plura individua sub una specie sine materia. Error'. Alius vero dicit sic: 'quod formae non recipiunt divisionem nisi secundum materiam. - Error, nisi intelligatur de formis eductis de potentia materiae'. Tertius dicit sic: 'quod, quia intelligentiae non habent materiam, Deus non posset plures eiusdem speciei facere - Error'.

\begin{tabular}{|l|l|l|l|l|l|}
\hline VERITAS & Porto Alegre & v. 41 & $\mathrm{n}^{2} 163$ & Setembro 1996 & p. 435-446 \\
\hline
\end{tabular}


blema del principio de individuación estaba en la mira de los profesores de París. Con este motivo el principio de individuación pasa a ser uno de los temas reiteradamente tratado por los pensadores de finales del siglo XIII: Enrique de Gante, Godofredo de Fontaines, Pedro de Auverna, Santiago de Viterbo, Rogerio Marston, Ricardo de Mediavilla, entre otros, escriben numerosas páginas sobre el principio de individuación. Pedro de Juan Olivo respondiendo a la inquietud de la época también va a detenerse a tratar este problema: 'an individuatio aliquid addat ad specificam essentiam individui', si la individuación añade algo a la esencia especifia del individuo.

Individuo significaba, para los pensadores de la segunda mitad del siglo XIII, en primer lugar ser indivisible o no poder ser dividido. Y ser indivisible, dicho de un ente sustancial, significa que esta sustancia individual no puede dividirse en sustancias especificamente semejantes v.g. Pedro es uno o indivisible porque no puede ser dividido en otros seres humanos especificamente semejantes a Pedro. A la vez, al decir de una sustancia que es un indivíduo, queremos decir que es única en cuanto indivídua y, por tanto, distinta de todas las demás sustancias individuales de la misma especie. El hecho de ser única la hace distinta de las demás sustancias de la misma especie v.g. Pedro es único y en consecuencia distinto de todos los demás seres humanos. El ser único hace a una sustancia radicalmente otro o distinto de toda otra sustancia, lo que entraña que es incomunicable, es decir, en cuanto única e indivídua, esta sustancia no tiene nada de común con cualquier otra sustancia.

\section{II - El indivíduo en Pedro de Juan Olivo}

\section{1 - Planteamiento del problema}

Pedro de Juan Olivo considera que la individuación de una sustancia deriva del ser mismo de la sustancia; si una sustancia existe, es una y en consecuencia es 'esta sustancia'. Al ser, a todo ser lo acompañan los transcendentales de bondad, verdad y unidad. Toda sustancia por el simple hecho de ser, es buena, verdadera y una. Por eso, Pedro de Juan Olivo afirma que "entre aquellas cosas que siguen en primer lugar al ente y a su ser está la unidad; la individuación parece ser lo mismo que la unidad". ${ }^{2}$ La individuación o aquello por lo que un indivíduo es indivíduo es, para Olivo, lo mismo que por lo que es uno.

La unidad transcendental del indivíduo, que acompaña necesariamente a toda sustancia individual, descarta de antemano la posibilidad de que el principio de individuación sea un accidente que la sustancia pueda tener o no tener, pueda tener así o de otra manera. Toda sustancia es indivídua, aún sin tener accidentes o antes de tenerlos. La individuación como unidad transcendental acompaña necesariamente a la esencia misma de cada sustancia y por tanto es anterior, al menos logicamente, a todo tipo de accidente que pueda añadirse a esa esencia sustancial.

2 Petrus Iannis Olivi, Quaestiones in secundum Ljbrum Setentiarum, Edición de Bernardo Jansen, Quarachi, 1992, vol. I, q. XII, p. 210: quoniam autem inter ea quae primo sequuntur ens et esse eius est unitas, individuatio autem videatur esse idem quod unitas (la traducción del latin es mía). 
Asomará la posibilidad de que la individuación pueda ser un accidente, en concreto el accidente cantidad, y en tal caso se-distinguiría realmente de la naturaleza común o esencia específica, pero obviamente no podrá aceptar tal posibilidad porque, para Olivo, el hecho de ser indivíduo deriva de su unidad transcendental, y por tanto del hecho de ser sustancia.

Una vez establecido que la individuación es esencial a toda sustancia individual, se pregunta Olivo "si la individuación añade algo a la esencia del indivíduo entendida especificamente".$^{3}$ Individuación y esencia específica aparecen en el planteamiento del problema como conceptos distintos e incluso contrapuestos: la individuación o aquello por lo que una sustancia es única e indivídua y esencia específica 0 aquello por lo que una sustancia se dice que pertenece a una especie y por tanto es común a todos los indivíduos de esa especie. La individuación hace a la sustancia única y distinta de las demás sustancias; la esencia específica la religa y la comunica con las demás sustancias de la misma especie. La individuación, o principio por el que una sustancia es ésta, añade algo a la esencia específica del indivíduo?

Pedro de Juan Olivo, como es su costumbre, va a discutir las razones en favor de que la individuación añade algo a la esencia específica y las razones en contra. Es importante analizar las razones que juzgamos más poderosas para captar el proceso del pensamiento que lo conducirá a esta o aquella conclusión.

La razón fundamental para defender que la individuación añade algo a la esencia específica deriva de la objetividad necesaria en todo conocimiento verdadero y en concreto de la objetividad de toda consecuencia o inferencia necesaria.

De la proposición "el hombre es" (A) no puede inferirse o descender a la proposición "este hombre es" (B). Esto quiere decir que B no está necesariamente encerrado en $\mathrm{A}$ y por tanto $\mathrm{B}$ expresa o significa algo más que A. "Este hombre" no es lo mismo que "hombre". Si la individuación nada añadiera a la esencia especifica, no habria razón alguna para que tal inferencia no fuera válida, ya que "hombre" y "este hombre" serian absolutamente la misma realidad. Luego "este hombre" añade algo a "hombre"."

Otra razón poderosa aporta Olivo para defender la opinión de que la individuación añade algo a la esencia específica y que se fundamenta en el principio lógico de que dos cosas iguales a una tercera son iguales entre si: $B=A ; C=A ; B=C$. $S i$ "este hombre es igual a hombre" y "aquel hombre es igual hombre"; entonces 'este hombre es igual a aquel hombre' lo cual es evidentemente falso. Luego el indivíduo 'este hombre' añade algo a la especie 'hombre' y no puede predicarse de ella, a saber no puede decirse: 'el hombre es este hombre'.

3 Op. cit., I, q. XII, p. 210: an individuatio aliquid addat ad essentiam individui specifice acceptam.

4 Op. cit., I, q. XI, p. 210-211, No. 1: a specie non descenditur ad individuum affirmando; non enim valet: est homo, ergo est hic homo; si autem individuatio significata per hoc pronomen 'hic' nihil addit ad hominem absolute seu specifice acceptum, nulla erit ratio in re quare non sequatur: est homo, ergo hic homo... et si nihil addit hoc ad illud, totaliter sunt eadem.

5 Op. cit., p. 211, No. 2: quaecumque uni et eidem omnino sunt eadem inter se omnino sunt eadem, alias periret tota ars syllogistica; ergo si duo individua unius speciei cum natura suae speciei omnino sunt eadem... inter ea essent omnino eadem. 
'Lo común en cuanto común no es propio de alguien' razona Olivo. Por tanto es preciso añadir algo a lo común que lo contraiga, lo limite y lo haga propio de alguien. Pero este añadido no puede ser absolutamente igual a lo común porque, en ese caso, sería común y no propio de alguien. 'Luego aquello por lo que lo común se contrae, tiene que ser algo realmente distinto de lo común'. ${ }^{6}$ Lo común o específico de un indivíduo no puede ser a la vez propio y particular de ese indivíduo. Para que lo común o específico se torne particular o individual es preciso que algo lo contraiga, lo limite y lo convierta en propio de alguien. Este algo que contrae, limita y convierte lo común en propio tiene que ser algo realmente distinto de lo común, porque de lo contrario sería absolutamente igual a lo común y él mismo común. Decir de la naturaleza específica que es lo común y haber afirmado que lo singular de este indivíduo es 'algo positivo' - que la contrae, la limita y hace propia - 'individuatio dicit aliquid positivum, sicut et individuum', y distinto de la naturaleza común, nos trae a la memoria numerosos textos de la Ordinatio escotista que sería escrita unos diez años más tarde.?

La individuación debe, según estas poderosas razones, añadir algo a la naturaleza común. Pero Olivo expone también una razón importante para defender la opinión contraria, a saber: la individuación no añade nada a la naturaleza común o específica. "Si la individuación añade algo realmente diferente a la naturaleza común, este algo será o algo esencial o algo accidental. No puede ser algo esencial porque en ese caso constituiría con la naturaleza específica una tercera esencia y por tanto otra especie distinta. Si añadiera algo esencial o sería la materia o alguna forma; no puede ser la materia porque la misma materia es común a muchas de la misma especie; por la misma razón no puede tampoco ser forma; y si fuese forma, sería una diferencia añadida a la naturaleza común como género. Tampoco puede ser algo accidental, porque ninguna cosa puede distinguirse esencialmente de otra sólo por accidentes...". Analicemos esta razón poderosa porque nos ayudará a comprender la posición de Olivo en torno al principio de individuación. Nada real añade la individuación a la naturaleza común o especifica, porque si algo real añadiera, esto sería 0 algo esencial 0 algo accidental. No puede ser algo accidental, porque ya hemos dicho que la individuación se deriva de su unidad transcendental o sustancial. No puede tampoco ser esencial porque en ese caso sería o materia o forma. No puede la individuación ser la materia porque la materia es común al menos a todas las materias de la misma especie. No puede ser forma, porque ésta igualmente es común a todas las formas de la misma especie; y si es una nueva forma distinta de la común, en ese caso constituiríamos una nueva especie cuyo género sería la naturaleza común y cuya diferencia sería la nueva forma, añadida por la individuación.

Añade la individuación algo real a la naturaleza común o específica? No añade nada real la individuación a la naturaleza específica? Olivo afirma textualmente

6 Op. cit., p. 211, No. 5: commune per id quod est commune impossibile est quod alicui appropietur, immo oportet quod sibi addatur aliquid contrahens, limitans et approprians; sed omne quod est omnino idem cum aliquo communi oportet quod sit commune; ergo illud per quod commune contrahitur oportet quod realiter differat ab ipso communi.

7 Estas Quaestiones ... fueron escritas hacia 1290, pues vieron la luz de la publicación en 1295. Juan Duns Escoto redactó y corrigió su Ordinatio a partir de 1300 hasta su muerte en 1308. 
que la primera opinión de que la individuación añade algo real a la naturaleza específica es mucho más común y más solemne, pero jamás afirma que sea la suya. ${ }^{8}$

\section{2 - Afirmación del indivíduo}

La opinión de Olivo va a partir del principio fundamental de que sólo existe lo individual y, por tanto, nada universal existe extramentalmente. Va a repetir de una manera tajante: "En éste no hay ninguna humanidad que simplemente no sea esta humanidad", "todo lo que de algún modo existe en las cosas fuera del entendimiento es particular e individuado", "Nada hay en las cosas común o universal de acuerdo a la verdad... sino que aquello a lo que el entendimiento atribuye la universalidad es en verdad y en sí mismo propio e indivíduo". ${ }^{9} \mathrm{Si}$ todo lo que existe es sólo lo singular o individual, no es preciso buscar algo real que contraiga o limite lo común o específico, ya que éste sencillamente no existe extramentalmente. Lo común y universal es en consecuencia producto del entendimiento humano y por tanto lo universal existe sólo mentalmente en nuestro entendimiento. En esta visión singularizante de la realidad extramental, la individuación deja de ser problema y más bien el gran problema es explicar nuestra universal manera de conocer y de hablar, como dirá muy bien unos años más tarde Guillermo de Ockham. ${ }^{10}$

Olivo se enfrenta al viejo problema epistemológico de los universales tan denodadamente discutido en los siglos anteriores. Si lo que existe es sólo singular e individual cómo conocemos de una manera universal?. Cómo decimos que Pedro que es hombre, que es animal, que es sustancia, que es ente? Por lo dicho anteriormente es impensable, para Olivo, cualquier tipo de realismo exagerado como el defendido en los siglos anteriores por autores como Anselmo de Canterbury o Guillermo de Champeaux. Al mismo tiempo hay que salvar la objetividad de nuestro conocimiento y por tanto hay que buscarle algún fundamento real a los conceptos universales que nosotros formamos de las realidades individuales. Por qué decimos de Dios que es bueno, justo, poderoso, infinito, eterno, es decir por qué atribuimos a Dios, realidad absolutamente simple, conceptos tan distintos?. Qué hay en la simplicidad absoluta de Dios que pueda justificar predicados tan diversos?

Pedro de Juan Olivo va a echar mano de algo nuevo, reiteradamente elaborado, para tratar de justificar objetivamente nuestra manera de conocer y de hablar, va a echar mano de las razones reales que existen distintas en una única e incluso simple realidad. Con las razones reales Olivo va a tratar de explicar la multiplicidad de

8 Op. cit., p. 226: alia opinio est praedicta multo communior et solemnior, prout credo, quod individuatio aliquid addat ad essentiam individui, ita quod vere est realis differentia inter individuans et individuatum.

9 "Nec in isto aliqua humanitas quae simpliciter non sit haec humanitas" (p. 228). "Quod nihil sit in rebus extra intellectum aliquo modo nisi particulare et individuatum" (p. 285). "In rebus nihil est secundum veritatem commune aut universale... sed illud cui intellectus attribuit universalitatem est vere secundum se proprium et individuum" (p. 230 , ad. 5 um).

10

Ockham, G., Ordinatio I, d. 2, q. 6, p. 197, 14-18: et ita quaelibet res extra animam se ipsa erit haec; nec est quaerenda aliqua causa individationis nisi forte causae extrinsicae et intrinsicae, quando individuum est compositum, sed magis esset quaerenda quomodo possibile est aliquid esse commune et universale. (Las citas son tomadas de las Opera theologica et philosophica, St. Bonaventure, NY, Franciscan Institute). 
atributos que predicamos de Dios y los atributos universales y univocos que predicamos de las distintas sustancias individuales. Con las razones reales, Olivo trata de explicar cómo y por qué, a partir de un universo de indivíduos o sustancias individuales, nosotros predicamos de ellos conceptos unívocos, comunes y universales, por qué decimos de Pedro que es hombre, que es animal, que es sustancia y que es ente.

\section{3 - Razones reales}

"Llaman razones reales a aquellas cuya verdad está plenamente en la cosa de manera que no se le atribuyen a las cosas por las maneras distintas de entenderlas sino por su propia naturaleza y verdad v.g. racional encierra la razón de ente, la razón de forma y la razón de tal forma por la que se distingue de irracional, así como la razón de verdadero, de bueno, y de parte; todas estas razones le competen esencialmente y se fundamentan naturalmente en su mismo ser". ${ }^{11}$ Descompongamos en proposiciones separadas el párrafo anterior:

1. Las razones reales son aquellas cuya verdad está plenamente en la cosa.

2. Las razones reales no se atribuyen a las cosas por las maneras distintas de entenderlas sino por su propia naturaleza y verdad real.

3. Racional encierra la razón de ente, la razón de forma y la razón de tal forma por la que difiere de irracional.

4. Estas razones le competen esencialmente y se fundamentan naturalmente en el ser mismo. Cuando nosotros atribuimos la racionalidad a Pedro estamos atribuyéndole las razones de ente, de forma y de tal forma por la que difiere de irracional. Y tales razones no se las predicamos a Pedro debido a la distinta manera que nosotros tenemos de entenderlo, es decir no son productos exclusivos de nuestro entendimiento, sino que estas razones se encuentran de verdad y naturalmente en Pedro. Estas razones le competen esencialmente a Pedro, expresan su esencia, aunque ninguna razón la exprese totalmente, ${ }^{12}$ y están fundamentadas en el ser mismo de Pedro. Estas razones no son productos exclusivos de nuestro entendimiento ni de nuestra particular manera de entender, sino que se encuentran de verdad en la cosa misma, pertenecen esencialmente a ella y se fundamentan en el ser mismo de la cosa. Es decir, estas razones que nosotros atribuimos a una cosa poseen un fundamento real, ya que se dan verdaderamente en la cosa.

El universo de Pedro de Juan Olivo es un conjunto de seres individuales y sólo de seres individuales; pero estos seres o sustancias individuales están constituídos por elementos múltiples capaces de ser captados por nuestro entendimiento. En efecto nuestro entendimiento puede distinguir: a) entre aquellas cosas que son dis-

11 Op. cit., vol. I, q. VII, p. 135: vocant rationes reales illas quarum veritas plenarie est in re, ita quod ex modo intelligendi vario non attribuuntur rebus, sed potius ex ipsa natura et veritate reali, ut verbi gratia ratione habet rationem entis et rationem formae et rationem talis formae per quam differt ab irrationali et habet in se rationem veri et boni et rationem partis; et omnes hae rationes essentialiter sibi competunt et in ipso esse naturaliter consistunt.

12 Op. cit., vol. I, q. VII, ad 4um, p. 143: quaelibet ratio dicit essentiam, nulla autem earum eam dicit totaliter. Las razones reales presentadas reiteradamente como expresando partes de la esencia, no parecen en ocasiones tan esenciales cuando por ejemplo se originan en nuestro cambio de posición con respecto a una sustancia material externa. 
tintas por el sujeto, el tiempo y el lugar, b) entre aquellas que son inseparables y c) entre dos razones que en la realidad no tienen distinción alguna aunque cada uma de ellas exista verdaderamente en la realidad. ${ }^{13}$ Es decir, nuestro entendimiento no solo puede distinguir entre cosas distintas que existen en distinto sujeto, en distinto tiempo o distinto lugar sino que también puede distinguir entre aquellas cosas que son inseparables. En una sustancia individual podemos distinguir entre realidades v.g. materia y forma que, siendo distintas realmente, son inseparables al menos en el orden actual establecido por Dios. Por último, podemos también distinguir con nuestro entendimiento entre dos razones que realmete no poseen distinción alguna aunque ambas existan verdaderamente en la realidad v.g. la razón de entendimiento y voluntad en Dios o la razón de la esencia y la razón de su individuación en una sustancia creada, las cuales no sólo son totalmente inseparables sino absolutamente la misma realidad. El distinguir entre estas dos razones no significa que entendamos el ser de una sin el ser de la otra o que una pueda ser sin la otra, sino simplemente que una razón no es la otra aunque sean absolutamente la misma cosa; entendemos una razón sin coentender la otra v.g. en Pedro podemos entender la razón de 'hombre' sin entender al mismo tiempo la razón de 'este hombre', aunque en Pedro sean ambas absolutamente la misma realidad. ${ }^{14}$

Nuestro entendimiento distingue entre dos o más razones en una sustancia individual, debido a que dichas razones existen verdaderamente en dicha sustancia; pero además, nuestro entendimiento establece entre ellas un orden, como sucede con las razones del entendimiento y la voluntad divinas o con las razones de esencia e individuación en Pedro. Nuestro entendimiento entiende una antes que la otra, debido a que entiende una como algo añadido y posterior a la otra. Así la voluntad en Dios es entendida después del entendimiento divino como algo añadido y posterior a él; de igual manera, en Pedro entendemos la razón de individuación después de la razón de esencia como algo añadido y posterior a ella ${ }^{15}$ Esto quiere decir que en Pedro podemos entender la razón de esencia u 'hombre' sin necesidad de entender a la vez la razón de individuación o de 'este hombre', o sea, entendemos 'hombre' en abstracto sin coentender su relación con el aquí y el ahora; por el contrario, la razón de individuación o 'este hombre' no puede ser entendida sin coentender la razón de la esencia y 'hombre'. La razón de esencia 'hombre', así entendida en abstracto y sin relación alguna con el aquí y el ahora, puede, en su abstracción e indiferencia, ser predicada de muchos indivíduos, aunque el entendi-

13 Op. cit., q. XIII, ad 2um, p. 248: Intellectus non solum potest distinguere inter ea quae sunt subiecto, tempore et loco distincta, sed et inter ea quae sunt inseparabilia, et non solum inter ista, sed etiam inter duas rationes quae in re nullam habent distinctionem, licet utraque veraciter sit in re.

14 Op. cit., p. 248: intellectus poterit distinguere inter rationen essentiae et inter rationem individuationis suae; non quod intelligat unum non esse sine altero aut posse esse, sed per hoc quod intelliget unum non esse aliud aut unam rationem non esse aliam, licet sint eadem res, et per hoc quod intelliget unum non intelligendo aliud.

Op. cit., q. XIII, ad 2um, p. 249: Inter diversas rationes, quamvis sint idem secundum rem, potest cadere ordo secundum intellectum, sicut inter rationem entis et substantiae et sicut in Deo inter rationem intellectus et voluntatis; unum enim cadit prius in intellectu quam reliquum, quia voluntas intelligitur se habere per additionem ad intellectum et per posterius; et talium primum potest intelligi ab intellectu absque hoc quod aliud apprehendatur. Sic autem se habet ratio individuationis ad rationem essentiae... 
miento advierta que esta universalidad de la razón de esencia 'hombre' no es verdadera y real sino un simple producto de nuestro entendimiento. La universalidad de la razón 'hombre' proviene de nuestra manera de entenderla como privada de individuación y de distinción, o como no coentendida con la individuación o con distinción alguna; por eso la razón 'hombre' podemos predicarla de muchos. ${ }^{16}$ Pero esto no quiere decir que la razón 'hombre' sea verdaderamente universal en la realidad o que el entendimiento entienda la razón 'hombre' como realmente universal, sino que la entiende universal en cuanto entendida en abstracto o en cuanto objeto, intelegible de esa manera para nuestro entendimiento. ${ }^{17}$ Tampoco hemos de entender que algo verdaderamente universal existe en nuestro entendimiento, sino sólo que algo es representado como universal en una especie intelectual y actual. Es decir, el universal real queda reducido en Olivo a una representación inteligible cuasi universal en el sentido de que dicha representación inteligible, en sí misma singular, en la que se prescinde de toda determinación e individuación pueda ser predicada de muchos. Qué quiere decir Pedro de Olivo con la expresión 'representación inteligible'? Es la clásica 'imagen inteligible' o 'fictum' del que hablan tantos autores y que Guillermo Ockham va a atacar tan despiadadamente?

$\mathrm{El}$ orden de anterioridad y posterioridad y la universalidad de las razones reales son productos de nuestro entendimiento y de la manera que éste tiene de captarlas y entenderlas, 'ratio superioritatis et universalitatis secundum quam homo et consimilia intelliguntur ut unum et idem in omnibus individuis non est in re, sed solum in intellectu' (Op. cit., q. XII, p. 228). Sin embargo, añade Olivo, algo existe en ellas que hace que nuestro entendimiento las entienda con este orden y con una representación cuasi universal. La pluralidad de razones reales ni poseen entre ellas diferencia alguna ni relación alguna real, pero tienen con respecto a nuestro entendimiento algo que las hace ser entendidas en ese orden y de una manera universal. Poseen con respecto a nuestro entendimiento una aptitud o capacidad de inteligibilidad por la que pueden ser captadas en un orden dado y de una manera universal. ${ }^{18}$

Nuestra manera de hablar, de razonar y de predicar sigue o se deriva no del modo de ser sino de nuestra manera de entenderlo; por eso de nuestra manera de entender las razones con un orden determinado y de una manera universal se deri-

16 Op. cit., q. XIII, ad 2um, p. 249: et ideo ratio essentiae potest intelligi absolute non-cointelligendo suam individuationem nec coitelligendo aliquem respectum eius ad hoc individuum vel ad hic et nunc. Et in tali ratione sic intellecta intellectus non apprehendit aliquam distinctionem et ideo, cum pluribus attribuit eam secundum hunc modum intelligendi, videtur quod unum et idem attributum esse pluribus...

17 Op. cit., q. XIII, ad 2um, p. 250: Ex hoc autem non sequitur quod res secundum veritatem sit universalis aut quod intellectus intelligat eam realiter esse universale, sed solum quod intelligat eam esse universalem, prout est sic intellecta et prout est intellectui tali modo obiecta. Unde etiam ex hoc non sequetur quod in intellectu sit aliqua vera universalitas, sed solum quod aliquid repraesentetur quasi universale $a b$ actu et especie intellectuali quasi universale et hoc modo dicto.

18 Op. cit., q. XIII, ad 4um, p. 251: Quamvis in re non sint tales habitudines, est tamen ibi aliquid unde intellectus potest eas formare et intelligere; quia in re est pluralitas rationum quae etsi secundum se non habeant differentiam neque ordinem et ita nec realem habitudinem, habent tamen per respectum ad intellectum, hoc est dictu; etsi in se non habeant, aptae natae sunt sic intelligi, in tali scilicet habitudine et in tali ordine. Sunt igitur in rebus tales habitudines, ad minus secundum aptitudinem intelligibilitatis. 
van las predicaciones, las consecuencias y las relaciones. ${ }^{19}$ De nuestra manera de entender las razones de 'hombre' y de 'este hombre'. y del orden con el que nosotros las entendemos, podemos decir 'Pedro es hombre' pero no podemos decir 'el hombre es Pedro' aunque Pedro y hombre sean totalmente idénticos en la realidad concreta de Pedro, debido a que la razón de Pedro es la razón de 'este hombre' individualizado, la cual la entendemos como añadiendo algo y como posterior a la razón de 'hombre'. De igual manera, de acuerdo a nuestra manera de entender las razones de 'hombre' y de 'este hombre', podemos inferir 'este hombre, luego hombre' pero no 'hombre, luego este hombre', debido a que en la razón de 'este hombre' está encerrada la razón de 'hombre' pero no viceversa. De igual manera, no es lo mismo decir 'Sortes es hombre' que 'Sortes es este hombre'. En efecto, en 'Sortes es hombre' se da una total identidad real entre sujeto y predicado, pero no se da una identidad de razones: la razón de 'Sortes' individualizada es distinta de la razón común de 'hombre'. Por el contrario en 'Sortes es este hombre' se da una total identidad real, pero también una total identidad de razones. ${ }^{20}$

Habría que acotar que nuestra manera de hablar, de razonar y de predicar sigue inmediatamente a nuestra manera de entender y solo mediatamente al modo de ser, para poder explicar la objetividad de nuestro entender y de nuestro lenguaje. Olivo recurre a las razones reales justamente buscando una justificación objetiva que explique nuestra manera universal de decir y predicar. Las razones reales son el fundamento real de nuestra manera de entender y de nuestra manera de hablar. Y si bien el orden entre las distintas razones de una sustancia individual y la universalidad de las mismas provienen de nuestra manera de entender esa sustancia, sin embargo Olivo termina buscándole un ancla de objetividad a ese orden y a esa universalidad en la aptitud o disposición natural de inteligibilidad de las razones reales para ser entendidas de esta manera y no de otra. 'aptae sunt sic intelligi, in tali scilicet habitudine et in tali ordine. Sunt igitur in rebus tales habitudines, ad minus secundum aptitudinem intelligibilitatis'. Por eso en nuestra correcta manera de predicar, de sacar consecuencias o inferir no se da falsedad alguna, debido a que la falsedad no proviene de la identidad real de lo significado sino de la identidad de la razón significada, la cual, como hemos visto, tiene también su fundamento real en la aptitud natural de inteligibilidad de las razones reales. ${ }^{21}$

19 Op. cit., q. XII, ad 3um, p. 229: quia tamen modus praedicandi sequitur modum intelligendi et variatur secundum rationum diversitatem, quamvis nulla sit realis diversitas. También op. cit., q. XIII, ad $4 u m$, p. 250: sicut intellectus distinguit inter duas rationes quae secundum rem non habent inter se diversitatem realem seu essentialem et sicut duae tales rationes possunt habere inter se ordinem prioritatis et posterioritatis per respectum ad intellectum quem non habent in re; ita et possunt ex tali modo intelligendi consimiles praedicationes, consequentiae et habitudines formari.

20 Op. cit., q. XII, ad 7um, p. 251: cum dico 'Sortes est homo', praedico omnino idem secundum rem, non tamen omnino idem secundum rationem; et ideo non oportet quod eadem sit praedicatio 'Sortes est homo' et 'Sortes est hic homo'.

21 Op. cit., q. XIII, ad 4um, p. 251: non erit in talibus nugatio, quia nugatio non fit ex identitate significati realis, sed ex identitate rationis significatae... 


\section{III - Conclusión}

'Todo lo que existe es singular y sólo existe lo singular'. En manos de Pedro de Juan Olivo el avance de lo singular o individual ha sido total. El universo extramental ha quedado reducido exclusivamente a un conjunto de sustancias individuales compuestas de dos principios realmente distintos, materia y forma, igualmente individuales. Los universales que de una u otra forma permanecían en la realidad van a ser totalmente eliminados y barridos por inútiles. Las expresiones tomistas que hablan de un universal in re e incluso de un universal ante rem no pueden tener cabida en el pensamiento singularizante de Olivo. Decir de las formas que, consideradas en sí mismas, son comunes o universales pero, por el echo de ser recibidas en una materia, se convierten en la forma determinada de esta cosa, tal como parecen opinar entre otros el Aquinate y Buenaventura, le parece a Olivo difícil de comprender. En efecto, si la auténtica realidad de la forma es 'ser universal o común' cómo puede, en su contacto con la materia, convertirse en singular y existir de una manera tan distinta - contraria, contradictoria con su auténtico ser - en la realidad extramental?. Por eso, la opinión de Olivo es tajante: nada universal o común existe verdaderamente en la realidad extramental. La realidad extramental ha quedado reducida a sólo un conjunto de indivíduos sin que en ellos exista nada, ni siquiera un rasgo, verdaderamente universal o común - los principios de materia y forma son también individuales. Lo universal conformará otro universo, totalmente distinto y separado del individual, y tendrá su orígen en la actividad inteligible del entendimiento. El universal es, para Olivo, un producto del entendimiento humano, sólo una 'representación cuasi universal' del entendimiento que responde a nuestra típica o humana manera de conocer lo individual. Cuando decimos de Pedro que es hombre o que es animal, es decir, cuando decimos de Pedro que es hombre como Juan o como José, estamos expresando simplemente nuestra manera de conocer intelectualmente a Pedro por la que lo conocemos como 'hombre' o privado de toda suerte de caracteres individuantes. Pero en manera alguna estamos afirmando que 'hombre en cuanto común' o desindividualizado exista o pueda existir en la realidad extramental. El universo real es totalmente distinto del universo inteligible y entre ellos ni hay ni puede haber punto alguno de contacto.

Para salvar el abismo existente entre esos dos universos - el real individual y el inteligible múltiple y universal - y explicar la objetividad de nuestro conocimiento y nuestro lenguaje, Olivo va a recurrir a las razones reales. Las razones reales de Olivo pretenden ser la justificación objetiva de todo nuestro conocimiento múltiple, de nuestro discurso lógico y de todo nuestro lenguaje. Su mismo nombre razones reales nos devela la misteriosa constitución de estos elementos que parecen moverse en una ontología que vacila entre el universo real de los indivíduos y el universo inteligible de las ideas o razones. Las razones reales son los elementos múltiples, constituyentes esenciales de la realidad individual, absolutamente idénticas al indivíduo existente y absolutamente idénticas entre sí. El universo real es, para Olivo, un conjunto de indivíduos o sustancias singulares compuestas a su vez de materia y forma también singulares, pero tanto la forma como la materia están constituídos esencialmente por una multiplicidad de razones reales. Fuera existen solo Pedro, 'esta piedra', 'este perro', 'esta casa', compuestos de una materia individuada y 
una forma individuada inseparables en el actual estado de cosas. Pero la forma de cada uno de ellos, v.g. la forma individuada de Pedro, está constituída esencialmente por una multiplicidad de razones reales tales como ente, sustancia, viviente, animal, hombre. ${ }^{22}$ Esta razones reales que existen verdaderamente en la forma de Pedro son absolutamente la misma realidad de Pedro y por tanto no se distinguen en absoluto entre ellas en Pedro. El entendimiento descubre y capta estas razones reales y las ordena y universaliza. Esto significa que el entendimiento, al descubrir y captar estas razones reales, les da un orden y construye en el entendimiento una representación inteligible cuasi universal de ellas: en la forma de Pedro, descubre y capta las razones reales de ente, sustancia, viviente, animal, hombre; las ordena y las universaliza. Ordenarlas entraña entender una como derivada o con posterioridad a otra y ésta con anterioridad a aquélla, así la razón real 'sustancia' es entendida como una razón real derivada y posterior a la razón real 'ente', pero anterior a la razón real 'viviente', es decir, entendemos 'ente' sin 'sustancia' pero no podemos entender 'sustancia' sin 'ente' y entendemos 'sustancia' sin 'viviente' pero no podemos entender 'viviente' sin sustancia. Universalizarlas supone entender las distintas razones como abstratas o provadas de toda suerte de individuación y sin relación al aquí y al ahora, v.g. cuando atribuimos la razón real de 'hombre' a Pedro, la estamos entendiendo como desindividualizada y por tanto como común a los distintos indivíduos humanos. Este orden y esta universalización de las razones reales no son arbitrarios y subjetivos sino que son producidos por nuestro entendimiento de acuerdo a una disposición o aptitud de inteligibilidad que las mismas razones reales poseen y que hacen que nuestro entendimiento las entienda de esa manera - aptae sunt sic intelligi in tali scilicet habitudine et in tali ordine. ${ }^{23}$ En resumen, la multiplicidad de atributos que predicamos de un indivíduo existente tienen su fundamento real en las múltiples razones reales que constituyen esencialmente ese indivíduo, y el orden y la universalidad de tales razones, producidos por el entendimiento, se enraizan objetivamente en la disposición o aptitud de dichas razones para ser entendidas de esa manera.

La dificultad se presenta cuando intentamos analizar 'la verdadera realidad' de las razones reales en el indivíduo que existe extramentalmente. Olivo insiste en que se identifican absolutamente en la realidad extramental entre sí y con la forma sustancial indivídual lo que significa que no podemos entender que 'una razón exista o pueda existir sin la otra' sino simplemente que 'una razón no es la otra' o que 'entiendo una razón sin entender la otra'. ${ }^{24}$ Cómo hemos de entender que 'una razón no es la otra' cuando ambas son absolutamente la misma cosa que el indivíduo. Cómo hemos de entender que 'la razón de hombre no es la razón de animal' cuando ambas son absolutamente la misma cosa que Pedro? Si 'la razón de animal'

22 También la materia individuada de Pedro encierra en su ser razones reales tales como la razón de su esencia y las razones de sus potencias con respecto a las formas. Ver a este respecto, Pérez Estévez, A. "La Materia en Pedro de Juan Olivo", Revista de Filosofia, Universidad del Zulia, No. 18, p. $33-61$.

23 Ver nota No. 17.

24 Op. cit., q. XIII, ad 2um, p. 249: non quod intelligat unum esse sine altero aut posse esse, sed per hoc quod intelliget unum non esse aliud aut unam rationem non esse, aut unam rationem non esse, licet sint eadem res, et per hoc quod intelliget unum non intelligendo aliud. 
es absolutamente la misma realidad que 'la razón de este hombre o Pedro' y si 'la razón de hombre' es absolutamente la misma realidad que 'la razón de este hombre - Pedro' en ese caso 'la razón de hombre y la razón de animal son absolutamente idénticas en la realidad'. Habrá que entender que 'una razón no es la otra' significa simplemente que 'entiendo una razón sin entender la otra' o que 'entiendo una razón como distinta de la otra'? Tal parece ser el sentido de algunos textos que hemos venido citando y, en ese caso, 'entender una razón sin entender otra razón' o 'entender una razón como distinta de otra razón' es el resultado de una acción diferencial y de un orden que nuestro entendimiento introduce en la realidad extramental, la cual es total y absolutamente indivídual y singular. Y esa diferenciación y orden de razones introducido por el entendimiento tiene como fundamento objetivo sólo la disposición o aptitud del indivíduo existente - o de su forma o materia individuadas - para ser entendido de esa manera, con una multiplicidad de razones y con un orden lógico entre esa multiplicidad de razones.

De este somero análisis realizado en torno al misterioso ser de las razones reales, lo que queda de real parece reducirse a la disposición o aptitud de las sustancias individuales nacidas para ser entendidas por conceptos, ideas o razones, elaborados por el entendimiento humano. El conocer, pensando en conceptos y razonando, y el hablar expresan más nuestra manera de entender las cosas que el ser mismo de la realidad extramental. Nuestra ciencia - universal y necesaria - es el resultado de un ordenamiento inteligible que nosotros hemos introducido al momento de entender la realidad individual. Pedro de Juan Olivo se ha instalado ya en un nominalismo conceptual. Las razones reales son los últimos residuos de un platonismo aristotélico agonizante que está dando paso a una nueva concepción del mundo real en la que sólo el singular tiene cabida. Los universales abandonan toda realidad extramental - sea ésta material o ideal - para encerrarse, como representaciones cuasi universales, en el entendimiento y la razón humanos en los que van a ser ordenados y combinados para manifestarse en el lenguaje y constituir la ciencia. De lo dicho podemos deducir que estas 'representaciones inteligibles cuasi universales' nada tienen ya de imágen o fictum de la realidad extramental, que ha quedado reducida a sólo y exclusivamente lo singular, con una disposición innata para ser entendida de la manera en que lo hacemos. 'Representación' nos lleva a la idea de hacer presente de nuevo la realidad, pero ciertamente no por medio de una imágen de alguna manera análoga con ella. Habrá que esperar a Guillermo de Ockham para que reduzca este 'verbum mentis' a signo natural del que derivará el lenguaje, hablado o escrito, como signo convencional. Ese será el reino del nominalismo puro y de la ciencia como puro lenguaje.

El triunfo de una ontología de lo singular o individual sobre la metafísica de lo universal, que es uno de los más destacados rasgos del comienzo de la Modernidad, tiene en Pedro de Juan Olivo un defensor destacado. 